\title{
Crowdsourced mapping of land use in urban dense environments: An assessment of Toronto
}

Eric Vaz

Department of Geography, Ryerson University

Jamal Jokar Arsanjani

Institute for Geography, Heidelberg University

Geo-located information is increasingly important for regional decision making and spatial assessment. Toronto has witnessed rapid demographic and economic change over the last decades, making the Toronto region the fourth largest economic centre in North America. From a policymaker's perspective, understanding land use for planning purposes is critical for better urban planning. Such information is, however, conditioned by classical surveying and sophisticated remote sensing techniques, which are often costly and spatially not feasible. Only local knowledge and information can really bridge this gap, as urban land use in denser urban regions is often very fine-grained information. Volunteered geo-information (VGI) sources are fundamental tools for the assessment of urban land use patterns. This article identifies land use patterns using VGI and offers a comparative assessment with traditionally classified land use features from remote sensing imagery for Toronto. A parcel-based analysis of the voluntarily shared spatial information is used and extended at a regional level, with an overall accuracy of 75 percent. Additionally, a per-class analysis confirms which land classes can be well (or poorly) mapped, and what level of disagreement exists between our approach and official records. The findings confirm a promising outlook for harnessing VGI for urban land use mapping for Toronto.

Keywords: OpenStreetMap, Volunteered Geographic Information, urban land use mapping, parcel-based analysis, Toronto

\section{La cartographie par externalisation ouverte de l'occupation du sol dans les milieux urbains denses : une évaluation à Toronto}

Les informations géolocalisées prennent de plus en plus d'importance dans les processus de prise de décision et dans l'évaluation spatiale au niveau régional. Toronto a connu une évolution démographique et économique rapide au cours des dernières décennies, de sorte que cette région est devenue le quatrième centre économique en Amérique du Nord. Pour améliorer l'aménagement du territoire, il est essentiel que les responsables politiques puissent intégrer l'occupation du sol dans la perspective urbanistique. Toutefois, ce type d'information dépend de techniques classiques d'arpentage et de télédétection très poussées, qui sont souvent dispendieuses et inapplicables sur le terrain. Il est possible de combler cette lacune en utilisant des savoirs et informations de nature locale, étant donné que les données sur l'occupation du sol dans les régions urbaines plus denses sont souvent très détaillées. Les sources d'information géographique volontaire (IGV) sont incontournables pour l'évaluation des modes d'occupation du sol en milieu urbain. Dans cet article, on distingue à l'aide d'ICV des modes d'occupation du sol qui font ensuite l'objet d'une évaluation avec les éléments d'occupation du sol conventionnels tirés d'un traitement d'images de télédétection à Toronto. Une analyse des parcelles est menée à partir de l'information spatiale partagée volontairement, puis est élargie à l'échelle régionale avec une précision globale de 75 percent. En outre, une analyse par classes d'occupation du sol permet de vérifier celles qui peuvent être bien (ou mal) cartographiées ainsi que l'écart entre notre

Correspondence to/Adresse de correspondance: Eric Vaz, Department of Geography, Ryerson, University, 350 Victoria St, Toronto, ON, M5B 2K3. Email/Courriel: evaz@ryerson.ca

The Canadian Geographer / Le Géographe canadien 2015, xx(xx): 1-10 
approche et les documents officiels. Il en ressort des perspectives prometteuses pour mettre à profit l'IGV afin de réaliser la cartographie de l'occupation du sol en milieu urbain à Toronto.

Mots clés : OpenStreetMap, information géographique volontaire, cartographie de l'occupation du sol en milieu urbain, analyse des parcelles, Toronto

\section{Introduction}

\section{Land use in the Greater Toronto Area}

The second largest country in the world, Canada is administratively divided into several provinces whose legislations may vary, posing a series of challenges regarding land use classification and shared knowledge of land cover. Its vast territory, which encompasses a landmass of almost $10,000,000 \mathrm{~km}^{2}$, has prompted increased efforts to classify, survey, and organize different land use data sources over the last decades. The challenge of land use classification for such large areas involves administrative and methodological planning; although spatial information at the provincial level becomes available, no integrated national longitudinal dataset exists that may be used for national land use research and evaluation (Vaz et al. 2012). In recent decades, we have witnessed unprecedented urbanization, resulting mostly from economic growth, and the need to offer adequate infrastructures and services to match these regional economic dynamics. As such, land use has changed drastically in Canada in the last decades-a clearer national-level understanding of both land use and these changes is of utmost importance to support better land use decision making (Pontius et al. 2004).

Using crowdsourced data to create a national repository of land use information could provide a cost-effective dataset that would aid in meeting these challenges. Canada has diverse land use characteristics, including the largest freshwater reserve in the world. Given its heterogeneous environment and extensive landmass, land use classification has tended to be focused on regions with anthropogenic activity. The Canadian wilderness, on the other hand, is sparsely classified and land use classification tends to be fragmented, arising from a variety of sources, including government-sponsored conciliatory projects initiated to implement agendas for sustainability water management, agricultural regions, urbanization, and forestry (Vaz et al. 2014). These projects, which enabled land use classification, have been tracked since the mid-1960s and often comprise different scales and levels of ancillary land use information depending on the federal and provincial levels of impact. However, federal and provincial governments have merged at times on joint efforts, such as the Canada Land Inventory (CLI), conducted between 1963 and 1995. This effort lasted over three decades and created a complete survey of land use information by means of air photography, existing maps, and metadata. The objective of the CLI was to develop an integrative approach to understanding Canadian agricultural suitability for crop production. The approach offered a class-level system from 1 to 7 , allowing the detection of land cover adequacy for agricultural activity.

Often, however, land use information is captured in a variety of independent data sources, and the nature of the information and the granularity of the classification system used can vary considerably according to the size of landmass, and the land use characteristics under consideration. In the case of the city of Toronto, the DMTI Spatial CanMap Route Logistics dataset provides basic land use data.

Change in urban environments in developed countries has become a ubiquitous phenomenon strongly resulting from rapid economic growth (Baus et al. 2014). In North America, this has led to a significant change in urban land use morphology, which is often in line with vertical growth and urban sprawl. Much of the urbanization over the last decades has been a result of migration flows from different regions throughout the world, but it has also been a result of household income increases, which have led to changes in the allocation of real estate and housing markets. In the southern Ontario region known as the Golden Horseshoe, this is particularly felt within the Greater Toronto Area, currently classified as the fourth largest economic hub in North America. Rapid demographic, complex land use, and economic transitions (Vaz and Aversa 2013) have led to a changing face in Canada's urban landscapes (Vaz and Bowman 2013). 
Urban regions and megacities are an inherent part of the future landscape of economically viable regions but face unprecedented challenges related to population influx, urban liveability, and transportation sustainability. In response, regions have had to rapidly transform to support population increases and accommodate growing commercial activity. These changes are often detrimental to surrounding agricultural, natural, and fragile ecological regions, reinforcing the need of sound strategies to cater to a world where 72 percent of the population will reside in urban environments by 2050. The Greater Toronto Area (GTA) constitutes an important example of this trend in urban growth given its rapid expansion in recent decades and its ongoing economic growth. With a total of six million inhabitants in its core metropolis, it is one of the most rapidly changing urban environments in the world and, with a projected growth of over ten million people by 2031, it is bound to become one of the world's megacities (Hemson Consulting 2013).

It is of utmost importance to consider land use classification as one of the prerequisites to cope with this trend of urban expansion. As a consequence, understanding land use has become an important component in the spatial planning of urban regions (Brown and Duh 2004), and in urban management (Masoomi et al. 2012). Land use is an important characteristic when assessing metropolitan regions. Land use can and should be defined by the integration and exploration of exclusive human activities on the land surface (Sherbinin 2002). Human activities in metropolitan areas have led to rapid changes in the traditional land cover typologies and are a result of the economic exploitation of the environment for anthropogenic purposes. Globalization and transportation have played a leading role in shaping land use at the regional and local levels, often to the detriment of small agricultural farms and rangeland, which until recently were land use types that hosted economic activity. In the case of Canada, this has been the situation since the early 1700s, when settlement activity by the Europeans shaped the region's land cover, particularly during the nineteenth century (Goldewijk 2001).

Although remotely sensed images play an important role in land use classification, land use mapping requires in situ data collection and expert knowledge regarding proper usage of land parcels (Townshend et al. 1987; Vaz et al. 2013). The collection of in situ data is of utmost significance to ensure adequate land use mapping, particularly in urban environments where high-resolution imagery is needed to obtain clear boundaries. Furthermore, human-dominated land use types are naturally in constant flux depending on economic activity, and real estate and commercial strategies. One such example is the Greater Golden Horseshoe, where agricultural land is increasingly destroyed due to the urban sprawl of the GTA. A comparative assessment carried out by Vaz and Bowman (2013) indicated that 5.80 percent of agricultural land and 5.47 percent of rangeland were lost between 2000 and 2010, as a consequence of the urban sprawl in the GTA's urban fringe. Remote sensing techniques have been highly beneficial in documenting these changes (Saadat et al. 2011; Qi et al. 2012).

In 1978, by the mandate of Environment Canada, the first database to assess land use changes was created, complementing the existing CLI, and bringing a higher level of spatial accuracy. The following objectives are fostered by the Canada Land Use Monitoring Program (CLUMP) (Natural Resources Canada 2013): (i) provide better awareness of the state of land resources, (ii) identify land use trends of national and regional importance, (iii) determine major areas of rapid change to avoid land use conflicts, and (iv) analyze land use changes and their consequences according to the impacts of government policies and existing programs. However, the standard scale of 1:50,000 used for land use classification, which is often available at the regional level within metropolitan areas, introduces some limitations for accurate metropolitan assessment in urban regions.

\section{Volunteered Geographic Information as land use sources}

Some efforts at producing land cover at the global, regional, and local scales have been made, suggesting the importance of such types of assessments; examples of global-scale and coarse-resolution approaches include GLC-2000 and MODIS (Friedl et al. 2002). In Canada, most land use models have naturally followed the integration of land cover maps, allowing a systemic assessment by creating higher accuracy (Jokar Arsanjani et al. 2013). The spatial accuracy and temporal availability of land use inventories is crucial for consistent mapping, which benefits land managers and planning. 
The advances of Web 2.0 and the availability of smart devices enable further exploration of the role of crowdsourced data in support of adequate land use classification. The considerable expenditure of time required from stakeholders to build an accurate and comprehensive land classification dataset would be substantially mitigated by a broader collaboration with the public, and the inclusion of crowdsourced information. Furthermore, the timeconsuming commitment that stakeholders must undertake to create an accurate knowledge of land would thus be mitigated by collaborative endeavours for land classification (Estima and Painho 2013a). The potential of the Web 2.0 technologies include the accessibility, accuracy, and feasibility of the gathering, editing, and joining of spatial information through hand-held devices (Fritz et al. 2009). Several web map services, such as ESRI's Base maps, Bing Maps, and Google Maps, have been at the forefront of allowing application programming interfaces for end-users to interact with highresolution spatial products. Collaborative mapping projects and initiatives, as outlined by Ramm and others (2011), have introduced locational positioning for land use information that is generated from users (Jokar Arsanjani et al. 2013). The result is a new spatial paradigm enabled by the huge potential of multi-user collaboration in which end-users generate, share, and edit geospatial information. This phenomenon is designated Volunteered Geographic Information (VGI) (Goodchild 2007) and holds a unique potential for stakeholders and policymakers to better plan growing urban environments.

Collaborative mapping projects involving VGI are often found in OpenStreetMap (OSM) (OpenStreetMap 2012). The availability of free data and frequent contributions (Koukoletsos et al. 2012) allows the ubiquitous generation of multi-temporal spatial information-a distinct advantage over proprietary datasets, which lack a consistent collaborative multi-temporal set. A spatial-statistical comparison, such as that conducted by Helbich and others (2012), suggests that official surveyed data lag with regard to OSM, which often shows higher accuracy in urban environments.

To date, few studies - namely those conducted by Jokar Arsanjani and others $(2013,2014)$, and Hagenauer and Helbich (2012) - have attempted to derive land use patterns from VGI. This research study attempts to offer an approach for incorporat- ing land use features from VGI through OSM. Using the Greater Toronto Area, we propose an approach for understanding the contribution of individuals with OSM. Our main investigation attempts to answer the feasibility of using these sources in large urban regions in developed countries as important tools in urban planning by offering adequate and scalable land use information within urban regions. Our hypothesis assumes that regions with a higher population density will foster greater numbers of VGI contributors, which in turn will add to the accuracy and specificity of land use information that is provided from VGI sources. This hypothesis is tested by a comparative assessment of available land use data without classified OSM datasets. Kappa indices are calculated to offer insights on how accurate OSM classification becomes in urban regions.

\section{Materials}

\section{OpenStreetMap dataset}

The OSM data of the study area were acquired through the OSM.planet file on 15 December 2013. These data were parsed into several feature sets, e.g., points, polylines, polygons, Points of Interest (POIs), buildings, land use, natural, roads, waterways, and railways. Detailed information on the map features and their characteristics are provided in the OSM wikipages. ${ }^{1}$ The official land use map of Toronto was provided by the Canadian Scholars GeoPortal, which was produced originally by DMTI Spatial Inc. for 2011. DMTI Spatial Inc. partnered with ESRI Canada, offering a precision-based understanding of street, rail, and routing data, and land use information. The land use data were developed using the National Topographic Data Base (NTDB) and reclassified, as well as realigned, with more upto-date sources obtained by the integration of 2001 Census, CanMap Streetfiles, and other data sources.

\section{Land use classification initiatives in Canada}

Study area. The Toronto Census Metropolitan Area (CMA) presents one of the densest urban environments in North America. At the regional

\footnotetext{
${ }^{1}$ http://wiki.openstreetmap.org/wiki/Map_Features
} 
level, it constitutes Toronto and four additional municipalities: York, Peel, Halton, and Durham. The region itself extends from its core at $43^{\circ} 38^{\prime} 33^{\prime \prime} \mathrm{N}$, $79^{\circ} 23^{\prime} 14^{\prime \prime} \mathrm{W}$ and has a total population of over six million inhabitants (Statistics Canada 2011). Its population density is significantly higher than Ontario's average with a total population density of 850 inhabitants per $\mathrm{km}^{2}$. The public transportation network extending in all directions is served by the municipal transportation system.

Toronto's economic growth has been at the forefront of North American economic growth. Its retail and commercial sectors have increased markedly in the last decade as a result of economic prosperity and demographic changes. The region has a diversified ethnic and cultural legacy. This cultural diversity has given rise to new economic opportunities, contributing to the municipal prosperity and the ongoing growth of commercial activity in the Greater Toronto Area.

However, as a consequence of this growth, the region has suffered significant urban sprawl.
Although this sprawl is still far from reaching Ontario's greenbelt, it must be considered and monitored by decision makers and stakeholders. Land use transitions have become a common phenomenon over the last decades in the region extending through the Golden Horseshoe, and land use policies, as well as an adequate awareness of land use types, are of utmost importance for maintaining and guaranteeing Toronto's urban sustainable environment. Figure 1 presents the physical extent of the chosen study area.

\section{Methods}

A combinatory approach was adopted to determine the land use classifications from the whole set of contributed features to OSM. These steps are specified in Figure 2: (i) data processing, (ii) delineation of land parcels, (iii) translation of OSM features to the target land use legend, (iv) association of an appropriate land use type to each land parcel according to the overlying attributes,

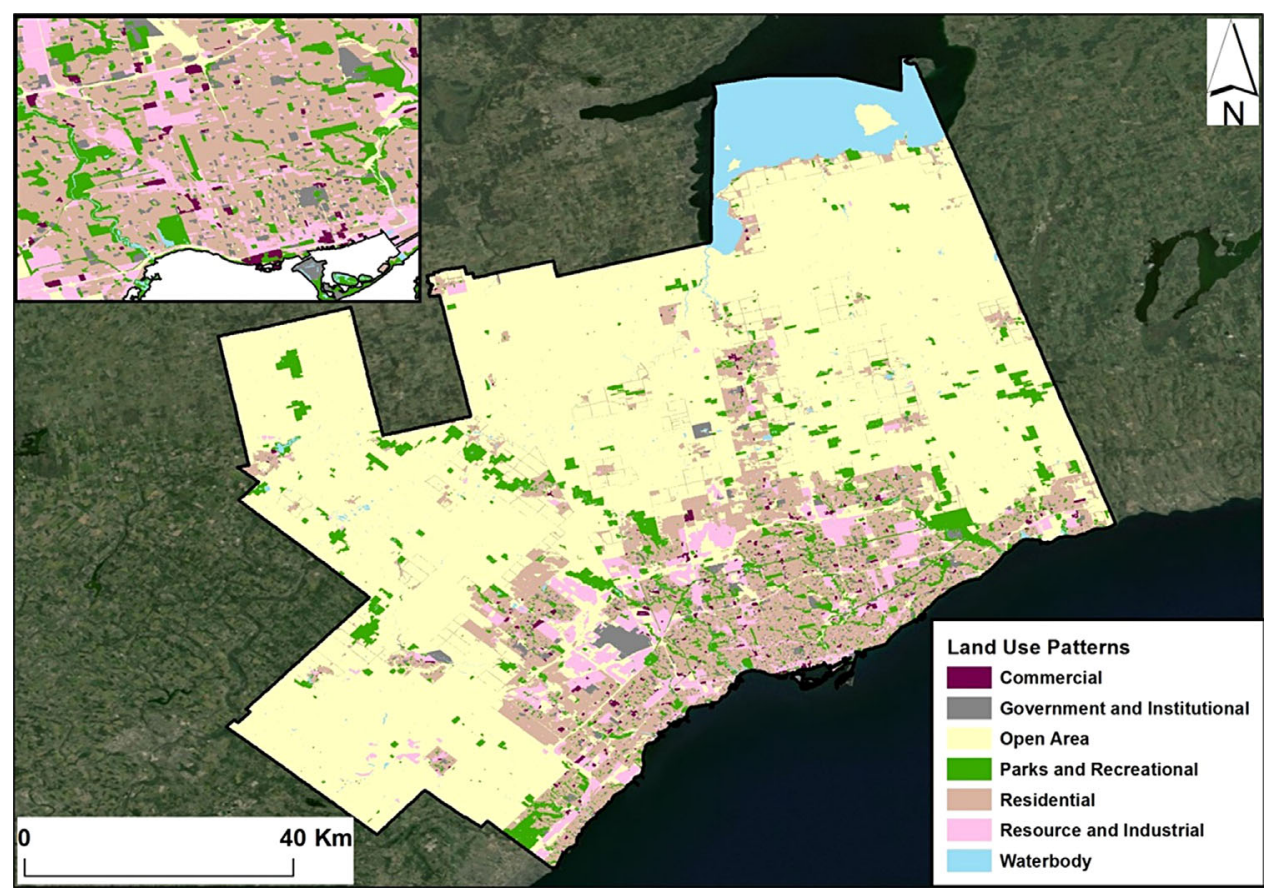

Figure 1

Geographical extent of the study area in Toronto

The Canadian Geographer / Le Géographe canadien 2015, xx(xx): 1-10 


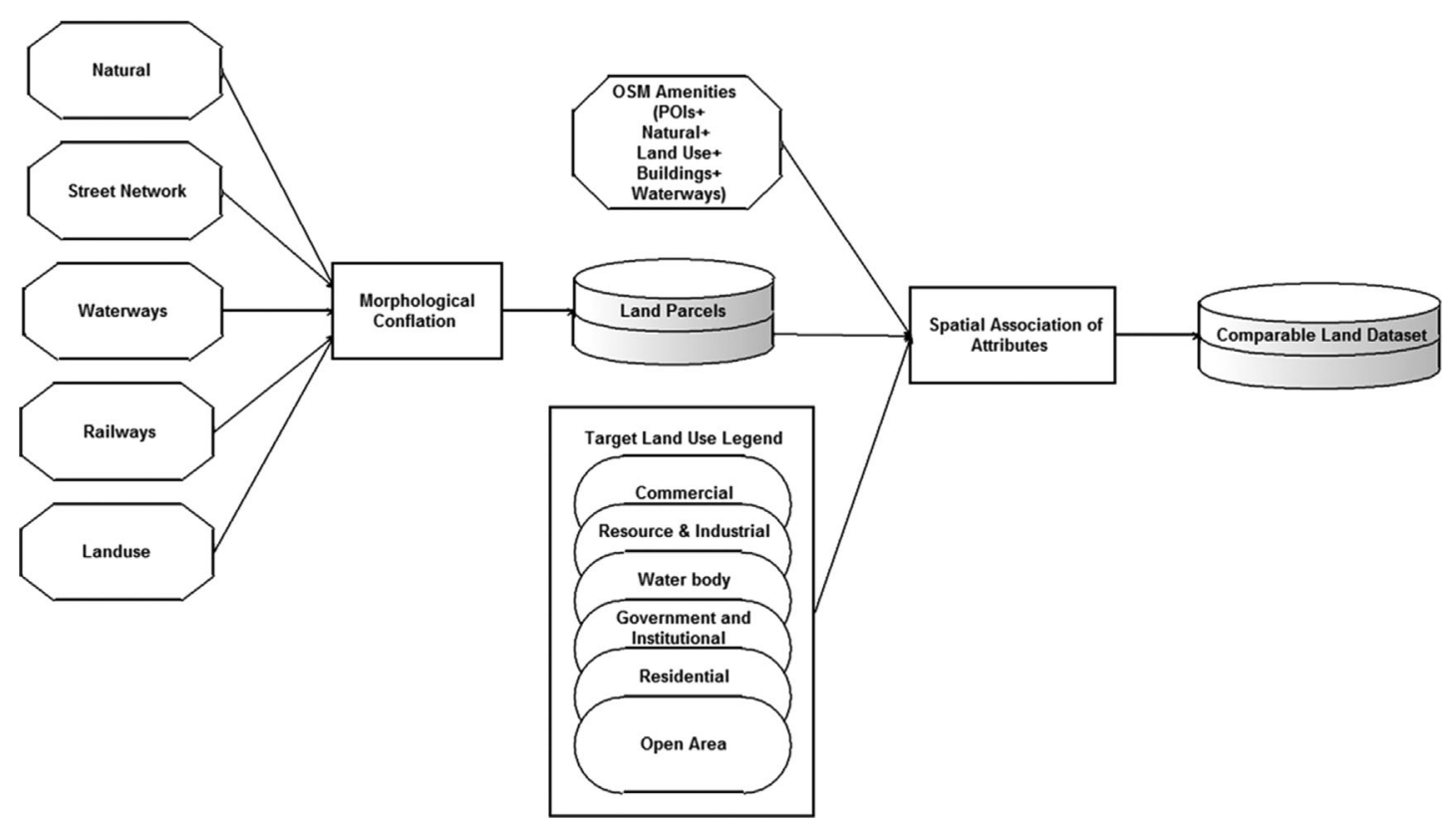

Figure 2

Workflow representing the implementation of the approach

and (v) interpretation of consequent land use types. OSM data were downloaded through the OSM.planet file; data pre-processing was furnished by the data provider.

The delineation of land use types poses a series of systemic challenges, and these challenges are traditionally bridged by airborne imagery and surveying, as well as enhanced image processing techniques, taking advantage of cadastral data types for accrued accuracy. Such processes are often very time-consuming and result in many hours of elaborate technical details that are difficult to translate at the global level. Traditional land use classification is heavily dependent on highresolution satellite imagery, which often must be purchased to guarantee the completeness of the area to be assessed and the accuracy of the results. Thus, land use classification, as an integrated process for the regional and urban measuring of anthropogenic land, introduces additional difficulties due to the physical demand of surveying within city cores. This challenge is particularly significant in larger urban areas, where traffic congestion, human activity, and commercial activity hinder potential surveying and accurate measurements. In this sense, local knowledge of land use and land use parcels within anthropogenic land use cores may be of utmost importance because it can result in a less expensive, quicker, and often more accurate approach than traditional land use classification techniques.

Our study adopts an integrative method by overlaying the existing datasets from OpenStreetMap, such as polygon features (e.g., land use and natural features) and linear features (e.g., roads, railways, waterways). These are overlaid and combined to partition the total urban environment into fine land segments and to delineate the boundary of each land parcel, as shown in Figure 3, and further compared visually with the official dataset. A visual comparison of the two maps in Figure 3 demonstrates that our approach results in high similarity and a more detailed texture of the retrieved land segments compared with the official dataset. Semantic similarity is of great importance for the urban land use comparison of OSM data (Ballatore et al. 2013). In the case of the GTA, no relevant semantic concerns of linguistic or object categorization were registered in the conversion of datasets. A statistical framework based on kappa index 


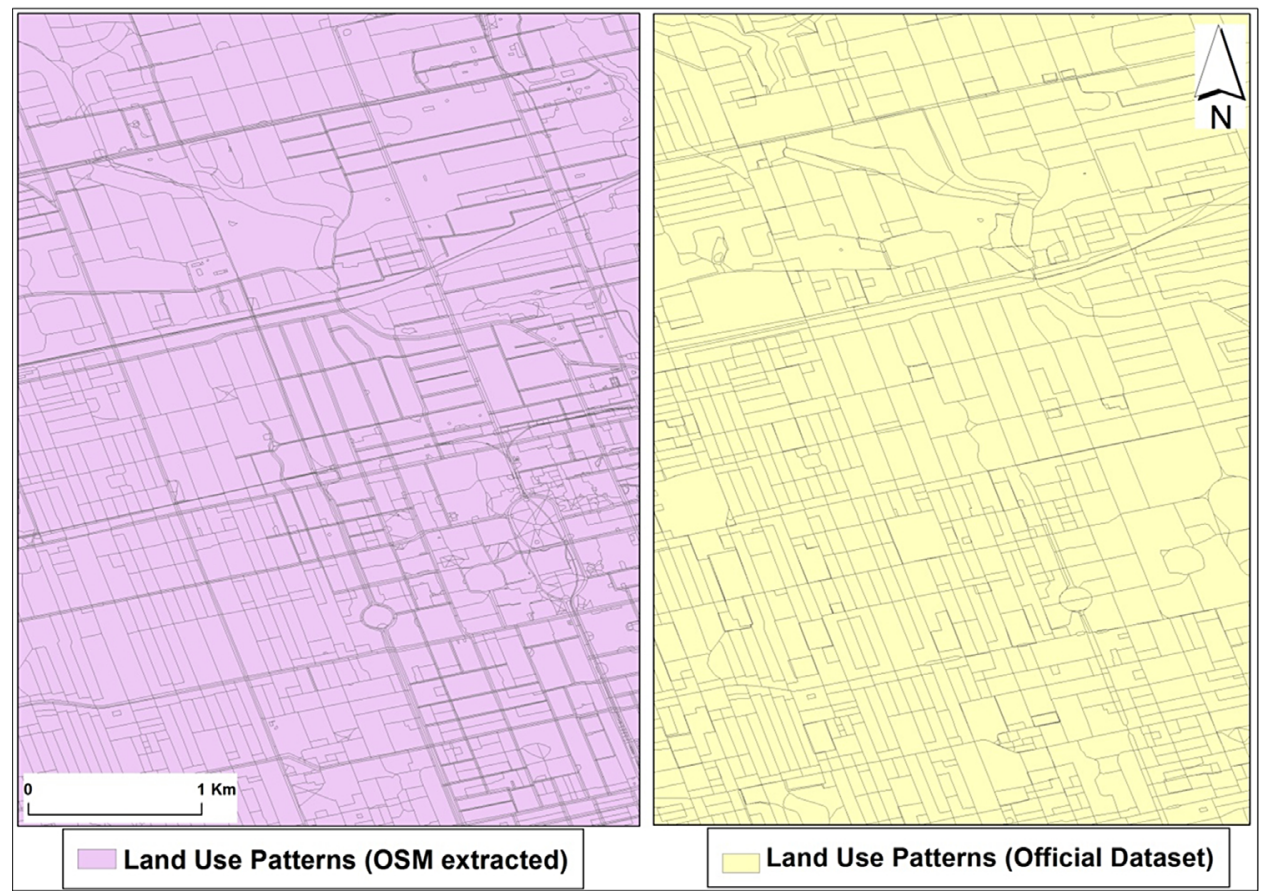

Figure 3

Close-up of the delineated spatial patterns of features from the official dataset (DMTI Spatial Land Use 2011: right) and derived from OpenStreetMap (left)

analysis was further conducted to allow a quantified perception of land use accuracy, as described in the results section.

A dictionary of attributes was designed to translate the OSM attributes into the land use classification scheme of the target dataset (official land use dataset). In doing so, the OSM attributes were renamed based on the target dataset, which is compatible with the domestic classification nomenclature. Thereafter, Point-in-Polygon, Polygon-in-Polygon, and spatial join analyses were implemented over the study area, which assigned the OSM attributes to each land parcel. For example, the functionalities of the points of interest-which identify public-related, health-related, leisurerelated, catering-related, accommodation-related, shopping-related, commerce-related, and tourismrelated points-were linked to their surrounding parcels. Similarly, building footprints, roads, waterways, railways, etc. were used for labeling land parcels. Those land parcels that could not be labeled were classified in the Open Area class.

\section{Results and discussion}

This section presents the results obtained in this study and their evaluation. Figure 4 presents the land use map obtained using the VGI approach (left) and the official land use dataset (right).

\section{Evaluation of results via confusion matrix}

A confusion matrix was generated to compare each land use class in the two datasets. Table 1 presents the confusion matrix and the coverage of each land type in the two datasets in terms of hectares, offering a comparative vision of the land use dynamics over the different categories.

The analysis of Table 1 and Figure 4 reveals important aspects of the regional dynamics of the land use classification properties for the GTA. An accuracy analysis reports an overall agreement of 75.6 percent between the VGI-based land use dataset and official dataset, and a Kappa index analysis confirms that the degree of matching between the 

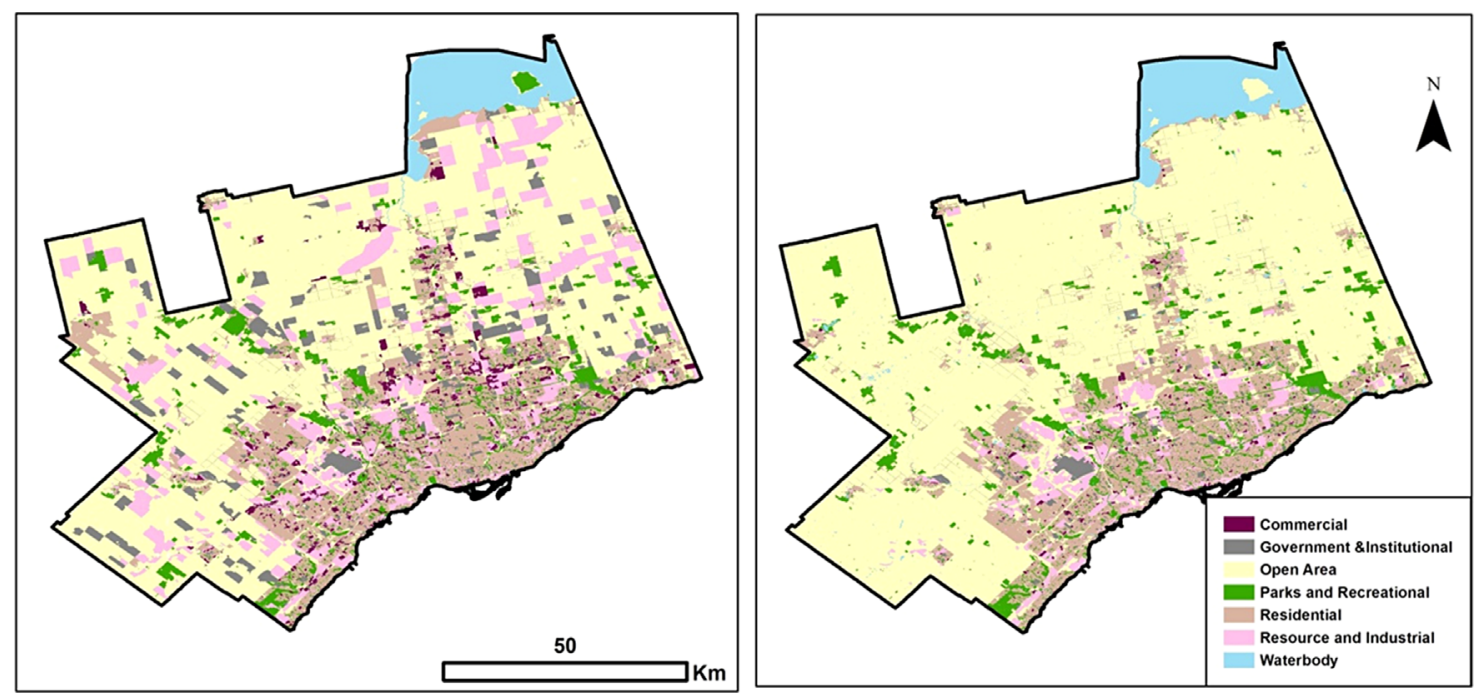

Figure 4

Extracted land use map of Toronto obtained using our approach (left) and the official dataset (right)

two maps was 65 percent. Both calculated indices are ranked as substantial (60 percent-80 percent) according to Landis and Koch (1997). However, a detailed per-class analysis based on the Producer's Accuracy was performed to determine the heterogeneity of the agreement between the two datasets. The Producer's Accuracy for water bodies was registered at 92.85 percent, suggesting that the geophysical boundaries between the VGI approach and the official dataset agreed very well. Parks and recreational areas, with an accuracy of approximately 82 percent, also offered a substantial classification according to Landis and Koch
(1997), who reported the feasibility of accurately mapping certain land use classes related to natural and ecological environments. All classifications offered accuracies greater than 50 percent, suggesting that land use from VGI can be effectively applied for land use classification purposes and dynamics.

Importantly, through comparing the resultant land use map and the reference land use map (Figure 4), it is evident that the major disagreements between the two maps were outside of the urban area; these areas are indicated as open areas in the reference dataset but were classified differently in the VGI approach. This, however, does not prove

Table 1

Confusion matrix of land use classes extracted using our approach (rows) and the official dataset (columns)

\begin{tabular}{|c|c|c|c|c|c|c|c|}
\hline & $\begin{array}{l}\text { Open } \\
\text { Area }\end{array}$ & Waterbody & $\begin{array}{c}\text { Parks and } \\
\text { Recreational }\end{array}$ & Residential & $\begin{array}{c}\text { Resource } \\
\text { and Industrial }\end{array}$ & Commercial & $\begin{array}{c}\text { Government } \\
\text { and Institutional }\end{array}$ \\
\hline Open Area & 342319 & 5 & 80 & 19034 & 5200 & 184 & 221 \\
\hline Waterbody & 0 & 31617 & 5 & 0 & 0 & 0 & 0 \\
\hline Parks and Recreational & 3332 & 954 & 34552 & 4074 & 618 & 145 & 200 \\
\hline Residential & 8485 & 218 & 1694 & 76566 & 1492 & 303 & 1919 \\
\hline Resource and Industrial & 53737 & 856 & 2258 & 5148 & 15571 & 210 & 619 \\
\hline Commercial & 5062 & 91 & 656 & 6388 & 5677 & 2009 & 2764 \\
\hline Government and Institutional & 27406 & 310 & 2987 & 4058 & 1637 & 400 & 5803 \\
\hline Total & 440341 & 34051 & 42232 & 115268 & 30195 & 3251 & 11526 \\
\hline Producer's Accuracy (\%) & 77.74 & 92.85 & 81.82 & 66.42 & 51.57 & 61.80 & 50.35 \\
\hline
\end{tabular}


that the reference dataset represents correct classes, and conversely, the achieved classes may represent a better indication of land use information. As the official dataset was generated in 2011, it may not provide the latest status of land use information because Toronto is a very vibrant and dynamic city. However, a detailed analysis of the disagreements between the two datasets should be performed to determine which source is more reliable. Furthermore, although the majority of land in Toronto suburbs is indicated as Open Areas in the official dataset, the VGI approach detected them as non-Open Areas that are used for other purposes. This likely played a role because the largest disagreement component between the two datasets was for the Resource \& Industrial, Government \& Institutional, and Open Area classes.

An integrated approach using VGI and highresolution satellite imagery may thus lead to important results that will allow a better understanding of urban land use typologies. It is the combination of different data sources through an integrated approach, as tested by Jokar Arsanjani and others (2013) for Vienna, that allows an accurate vision of the land uses of urban areas. Although Europe has been at the forefront of the contributions of VGI-related approaches for land use classification (Neis et al. 2013; Jokar et al. 2014), there is the potential for the GTA to benefit from these approaches to land use classification, given the rapid increase in use of mobile and smart phone devices.

\section{Conclusions and future work}

VGI is a promising endeavour for the future land use classification of growing urban regions in the developed world. The advances in contributing technologies and the increased population density within larger metropolitan regions suggest that collaborative projects, such as OSM, can support the land use planning agenda. In the case of Canada, where land use classification poses great logistical challenges due in part to issues of regional administration and jurisdiction, and cost efficiency, the integration of land use classification through VGI is a very welcome approach for more accurate land use information. VGI-based approaches for land mapping have been further tested by Geo-wiki (Fritz et al. 2009) for global coverage, and promising results for VGI-based mapping of land features were achieved.

The spatiotemporal result of land use classification that becomes available through this integrative approach further allows the sharing of information that portrays spatial dynamics vis-à-vis land use change in Canada, one of the most important phenomena to consider in rapidly changing urban regions. Toronto, which is on the verge of becoming a megacity in the coming decades, needs public information and expert knowledge to cope with a sustainable urban future in order to mitigate the risks for Ontario's greenbelt and offer adequate monitoring of the urban sprawl. The collective force brought by a Web 2.0 context in lieu of traditional surveying methods suggests a very promising approach to measuring, monitoring, and assisting land use changes and transitions in rapidly changing environments.

\section{References}

Ballatore, A., M. Bertolotto, and D. C. Wilson. 2013. Geographic knowledge extraction and semantic similarity in OpenStreetMap. Knowledge and Information Systems 37(1): 61-81.

Baus, P., U. Kován, E. Pauditšová, I. Kohutková, and J. Komorník. 2014. Identification of interconnections between landscape pattern and urban dynamics-Case study Bratislava, Slovakia. Ecological Indicators 42: 104-111.

Brown, D. G., and J. D. Duh. 2004. Spatial simulation for translating from land use to land cover. International Journal of Geographical Information Science 18(1): 35-60.

Estima, J. and M. Painho. 2013a. Exploratory analysis of OpenStreetMap for land use classification. In GEOCROWD '13 Proceedings of the Second ACM SIGSPATIAL International Workshop on Crowdsourced and Volunteered Geographic Information. New York, NY: ACM, pp. 39-46.

Friedl, M. A., D. K. McIver, J. C. F. Hodges, X. Y. Zhang, D. Muchoney, A. H. Strahler, C. E. Woodcock, S. Gopal, A. Schneider, A. Cooper, A. Baccini, F. Gao, and C. Schaaf. 2002. Global land cover mapping from MODIS: Algorithms and early results. Remote Sensing of Environment 83(1-2): 287-302.

Fritz, S., I. McCallum, C. Schill, C. Perger, R. Grillmayer, F. Achard, F. Kraxner, and M. Obersteiner. 2009. Geo-Wiki.Org: The use of crowdsourcing to improve global land cover. Remote Sensing 1(3): 345-354.

Goldewijk, K. 2001. Estimating global land use change over the past 300 years: The HYDE database. Global Biogeochemical Cycles 15(2): 417-433.

Goodchild, M. F. 2007. Citizens as sensors: The world of volunteered geography. GeoJournal 69(4): 211-221.

Hagenauer, J., and M. Helbich. 2012. Mining urban land use patterns from volunteered geographic information by means of genetic algorithms and artificial neural networks. International Journal of Geographic Information Science 26(6): 963982. 
Helbich, M., C. Amelunxen, and P. Neis. 2012. Comparative Spatial Analysis of Positional Accuracy of OpenStreetMap and Proprietary Geodata. International GI_Forum. Salzburg, Austria.

Hemson Consulting. 2013. Greater Golden Horseshoe Growth Forecasts to 2041: Technical Report Addendum. Toronto, ON: Hemson Consulting: Canada. http://www.hemson.com.

Jokar Arsanjani, J., M. Helbich, W. Kainz, and B. A. Darvishi. 2013. Integration of logistic regression, Markov chain and cellular automata models to simulate urban expansion. International Journal of Applied Earth Observations and Geoinformation 21: $265-275$.

Jokar Arsanjani, J., W. Kainz, and A. J. Mousivand. 2011. Tracking dynamic land-use change using spatially explicit Markov Chain based on cellular automata: The case of Tehran. International Journal of Image and Data Fusion 2(4): 329-345.

Jokar Arsanjani, J., E. Vaz and M. Bakillah. 2014. Towards initiating OpenLandMap founded on citizens' science: The current status of land use features of OpenStreetMap in Europe. In Proceedings of the 17th AGILE conference, Castellon, Spain. http://repositori.uji.es/xmlui/bitstream/ handle/10234/98805/35agile2014_134.pdf?sequence $=1$.

Koukoletsos, T., M. Haklay, and C. Ellul. 2012. Assessing data completeness of VGI through an automated matching procedure for linear data. Transactions in GIS 16(4): 477-498.

Landis, J. R., and G. G. Koch. 1977. The measurement of observer agreement for categorical data. Biometrics 33(1): 159-174.

Masoomi, Z., M. S. Mesgari, and M. Hamrah. 2012. Allocation of urban land uses by Multi-Objective Particle Swarm Optimization algorithm. International Journal of Geographical Information Science 27(3): 542-566.

Neis, P., D. Zielstra, and A. Zipf. 2013. Comparison of volunteered geographic information data contributions and community development for selected world regions. Future Internet 5(2): 282-300.

OpenStreetMap. 2012. OpenStreetMap wikipage on Quality Assurance retrieved at http://wiki.openstreetmap.org/wiki/ Quality_Assurance.

Pontius, Jr., R. G., D. Huffaker, and K. Denman. 2004. Useful techniques of validation for spatially explicit land-change models. Ecological Modelling 179(4): 445-461.
Qi, Z., A. G. O. Yeh, X. Li, and Z. Lin. 2012. A novel algorithm for land use and land cover classification using RADARSAT-2 polarimetric SAR data. Remote Sensing of Environment 118(15): 21-39.

Ramm, F., J. Topf, and S. Chilton. 2011. OpenStreetMap: Using and enhancing the free map of the world. 3rd ed. Cambridge: UIT Cambridge Ltd.

Saadat, H., J. Adamowski, R. Bonnell, F. Sharifi, M. Namdar, and S. Ale-Ebrahim. 2011. Land use and land cover classification over a large area in Iran based on single date analysis of satellite imagery. ISPRS Journal of Photogrammetry and Remote Sensing 66(5): 608-619.

Sherbinin, A. 2002. A CIESIN thematic guide to land-use and land-cover change (LUCC). Palisades, NY: Center for International Earth Science Information Network (CIESIN), Columbia University.

Statistics Canada. 2011. The Canadian population in 2011: Population counts and growth. Ottawa, ON: Statistics Canada. http://www12.statcan.gc.ca/census-recensement/2011/as-sa/ 98-310-x/98-310-x2011001-eng.pdf.

Vaz, E., P. Nijkamp, M. Painho, and M. Caetano. 2012. A multiscenario forecast of urban change: A study on urban growth in the Algarve. Landscape and Urban Planning 104(2): 201-211.

Vaz, E., and J. Aversa. 2013. A graph theory approach for geovisualization of land use change: An application to Lisbon. Journal of Spatial and Organizational Dynamics 1(4): 254264.

Vaz, E., and L. Bowman. 2013. An application for regional coastal erosion processes in urban areas: A case study of the Golden Horseshoe in Canada. Land 2(4): 595-608.

Vaz, E., T. Noronha, and P. Nijkamp. 2014. Exploratory landscape metrics for agricultural sustainability. Agroecology and Sustainable Food Systems 38(1): 92-108.

Vaz, E., A. Buckland, and K. Worthington. 2013. A Regional Spatial-retrofitting Approach (RSRA) to geovisualise regional urban growth: An application to the Golden Horseshoe in Canada. Journal of Spatial and Organizational Dynamics 1(4): 229-240.

Wästfelt, A., and W. Arnberg. 2013. Local spatial context measurements used to explore the relationship between land cover and land use functions. International Journal of Applied Earth Observation and Geoinformation 23: 234-244. 